\title{
SISTEM INFORMASI PESAWAT TANPA AWAK (DRONE) BERBASIS APLIKASI ANDROID
}

\author{
Berlian Sigit Sugiarto ${ }^{1}$, Astriana Mulyani ${ }^{2}$, Hafis Nurdin ${ }^{3}$ \\ Program Studi Teknik Informatika ${ }^{1,2,3}$ \\ Sekolah Tinggi Manajemen Informatika dan Komputer Nusa Mandiri Jakarta ${ }^{1,2,3}$ \\ $\underline{\text { berliansigit23@gmail.com }}{ }^{1}, \underline{\text { astriana.atm @nusamandiri.ac.id }^{2}}, \underline{\text { hafis.nnr@nusamandiri.ac.id }^{3}}$
}

\begin{abstract}
Abstrak
Drone merupakan pesawat tanpa awak yang dikendalikan dari jarah jauk oleh auto pilot atau mampu mengendalikan dirinya sendiri dan menggunakan hukum aerodinamika untuk menganggkat diri sendiri agar bisa melakukan penerbangan. Pemanfaatan pesawat drone adalah untuk pengambilan gambar berupa foto ataupun video. Drone tidak boleh dioperasikan pada ketinggian lebih dari 150 meter $(500 \mathrm{ft})$, artinya penggunaan drone sebagai aktivitas bermain dan hobi hanya dibolehkan terbang di bawah 150 meter. Untuk membantu masyarakat dalam memahami aturan penggunaan drone maka diperlukan media interaktif yang dapat menarik minat masyarakat dalam mempelajarinya. Android adalah jenis smartphone yang paling banyak digunakan oleh masyarakat saat ini. Aplikasi Sistem Informasi Pesawat Tanpa Awak (Drone) Berbasis Aplikasi Android ini di rancang menggunakan software android studio versi 3.6.3 dan bahasa pemrograman java. Pengembangan sistem menggunakan metode waterfall yaitu analisa, desain, code generation, testing dan support. Aplikasi ini menampilkan beberapa informasi seperti: Regulasi, Zona Merah, Jenis Drone, Tips, dan Tentang penulis. Dengan adanya aplikasi ini diharapkan dapat membantu masyarakat untuk mengetahui bahwa pesawat tanpa awak (drone) itu tidak bisa terbang disembarang tempat.
\end{abstract}

Kata Kunci: Android, Mobile Programming, Drone, Waterfall

\section{PENDAHULUAN}

Di zaman yang sudah berkembang sangat pesat ini, khususnya di bidang teknologi yang terlihat signifikan. Banyak teknologi baru yang bermunculan, salah satu contohnya adalah pesawat tanpa awak (drone). Dengan alat ini dapat mempermudah pekerjaan manusia seperti : memantau keadaan saat banjir, kemacetan, dll.

Drone merupakan pesawat tanpa awak yang dikendalikan dari jarah jauk oleh auto pilot atau mampu mengendalikan dirinya sendiri dan menggunakan hukum aerodinamika untuk menganggkat diri sendiri agar bisa melakukan penerbangan.[1]

Pemanfaatan pesawat drone adalah untuk pengambilan gambar berupa foto ataupun video. Kelebihan pesawat drone adalah dapat memberikan sudut pengambilan gambar yang tidak memungkinkan dilakukan oleh seorang kameramen.[2]

Drone tidak boleh dioperasikan pada ketinggian lebih dari 150 meter (500 ft), artinya penggunaan drone sebagai aktivitas bermain dan hobi hanya dibolehkan terbang di bawah 150 meter. Adapun untuk aktivitas bisnis jika ingin terbang di atas 150 meter harus mendaftarkan drone serta pilotnya dengan mengajukan ijin terbang ke Direktorat Jenderal Perhubungan Udara.[3]

Masyarakat perlu memahami ketentuan hukum penggunaan drone agar tidak melanggar hak publik maupun negara Republik Indonesia yang menguasai wilayah udara. Pengoperasian drone di Indonesia tidak dapat sembarangan karena pengaturan khusus perihal drone sendiri diatur dalam Peraturan Menteri Perhubungan Republik Indonesia Nomor No 47 Tahun 2016 tentang Pengendalian Pengoperasian Pesawat Udara Tanpa Awak Di Ruang Udara yang Dilayani Indonesia.

Peraturan Pemerintah Nomor 04 Tahun 2018 mengatur tentang pengamanan wilayah udara Republik Indonesia. Pesawat tanpa awak atau drone tidak boleh diterbangkan di area penerbangan dan tempat-tempat vital seperti militer. Walaupun peraturan tersebut sudah berlaku masih saja ada sekelompok orang yang nekat untuk menerbangkan drone di wilayah terlarang.

Maka dari itu penulis akan membuat sebuah aplikasi yang berisi informasi mengenai regulasi menerbangkan drone, zona merah (wilayah yang tidak boleh menerbangkan drone), jenis-jenis drone, tips menerbangkan drone dan tentang.

\section{LITERATUR DAN METODE}

\section{Konsep Dasar Program}

\section{A. Program}

Program adalah kumpulan intruksi yang digunakan untuk mengatur komputer agar

\section{JISICOM (Journal of Information System, Informatics and Computing)}

http://journal.stmikjayakarta.ac.id/index.php/jisicom Telp.+62-21-3905050, e-mail:jisicom@stmikjayakarta.ac.id, jisicom2017@gmail.com 


\section{Journal of Information System, Informatics and Computing}

melakukan suatu tindakan tertentu[4]. Tanpa program, komputer hanyalah sebuah mesin yang tidak dapat melakukan tugas apapun yang diinginkan oleh penggunanya[5].

Fungsi program yaitu :

a. Mengatur hubungan antar hardware agar dapat bekerja secara bersamaan. Dengan demikian, hardware bisa bekerja sesuai dengan fungsinya masing-masing tanpa ada hambatan.

b. Untuk mengindentifikasi program. Misalnya, File Explorer yang berperan menjadi tempat untuk mengakses berbagai jenis program lainnya yang tersimpan dalam komputer.

c. Menghubungkan antara program dengan hardware.

d. Menerjemahkan instruksi kedalam bahasa mesin. Contohnya seperti compiler dari bahasa pemrograman, seperti Visual Basic, Java, C++ dan lain-lainnya.

B. Java

Java adalah perangkat lunak produksi Sun Microsystem Inc., yang merupakan perangkat lunak pemrograman untuk beberapa tujuan (multi purpose), dapat berjalan di beberapa sistem operasi (multipatform), mudah dipelajari dan powerful. Aplikasi-aplikasi yang dapat dibuat dengan Java meliputi pemrograman web (web programing), pemrograman desktop (desktop programing), pemrograman handphone/mobile (mobile programing)[6].

\section{Android}

Android adalah sistem operasi bersifat open source berbasis Linux dirancang untuk perangkat seluler layar sentuh seperti telepon pintar dan komputer tablet. Android awalnya dikembangkan oleh Android, Inc., dengan dukungan finansial dari Google, yang kemudian membelinya pada tahun 2005. Sistem operasi ini dirilis secara resmi pada tahun 2007, bersamaan dengan didirikannya Open Ponsel Android pertama mulai dijual pada bulan Oktober 2008[7].

\section{Android Studio}

Android studio adalah IDE (Integrated Development Environment) resmi untuk pengembangan aplikasi Android dan bersifat open source atau gratis. Peluncuran Android Studio ini diumumkan oleh Google pada 16 mei 2013 pada event Google I/O Conference untuk tahun 2013[8].

E. Software Devlopment Kit (SDK)

Software Devlopment Kit (SDK) adalah tools Aplication Programming Interface (API) yang diperlukan untuk memulai pengembangan suatu aplikasi pada platform android menggunakan bahasa pemrograman java[9].

\section{F. Java Development Kit (JDK)}

Java Development Kit (JDK) adalah sekumpulan perangkat lunak yang dapat digunakan untuk mengembangkan perangkat lunak yang berbasis Java[8].

\section{G. Adobe Photoshop}

Adobe Photoshop atau biasa disebut Photoshop adalah perangkat lunak editor citra buatan Adobe Systems yang dikhususkan untuk pengeditan foto/gambar dan pembuatan efek. Perangkat lunak ini banyak digunakan oleh fotografer digital dan perusahaan iklan sehingga dianggap sebagai pemimpin pasar (market leader) untuk perangkat lunak pengolah gambar/foto, dan bersama Adobe Acrobat, dianggap sebagai produk terbaik yang pernah diproduksi oleh Adobe Systems[11].

H. Unifield Modeling Language (UML)

Unifield Modeling Language merupakan salah satu metode pemodelan visual yang digunakan dalam perancangan dan pembuatan sebuah software yang berorientasikan pada objek. UML merupakan sebuah standar penulisan atau semacam blue print yang didalamnya terdapat bisnis proses dan penulisan kelas-kelas dalam sebuah bahasa yang spesifik.

Berikut adalah diagram UML yang sering digunakan dalam pengembangan sebuah sistem[12]:

a. Use Case: Merupakan gambaran dari fungsionalitas yang diharapkan dari sebuah sistem, dan merepresentasikan sebuah interaksi antara aktor dan sistem. Didalam use case terdapat actor yang merupakan sebuah gambaran entitas dari manuasia atau sebuah sistem yang melakukan pekerjaan di sistem.

b. Activity Diagram: Merupakan gambaran alir dari aktivitas-aktivitas didalam sistem yang berjalan.

c. Sequence Diagram: Menggambarkan interaksi antar objek didalam dan di sekitar sistem yang berupa message yang digambarkan terhadap waktu.

\section{JISICOM (Journal of Information System, Informatics and Computing)}




\section{Journal of Information System, Informatics and Computing}

d. Deployment diagram digunakan untuk menggambarkan, memvisualisasikan, menspesifikasikan serta mendokumentasikan suatu proses yang terjadi dalam sebuah sistem berbasis OOP (object orientied programming) yang akan dibangun[13].

\section{Pengujian Sistem}

Black Box Testing merupakan pengujian yang berfokus pada spesifikasi fungsional dari perangkat lunak, tester dapat mendefinisikan kumpulan kondisi input dan melakukan pengetesan pada spesifikasi fungsional program[14].

Keuntungan dari penggunaan metode black box testing adalah[15]:

1. Penguji tidak perlu memiliki pengetahuan tentang bahasa pemrograman tertentu.

2. Pengujian dilakukan dari sudut pandang pengguna, ini membantu untuk mengungkapkan ambiguitas atau inkonsistensi dalam spesifikasi persyaratan.

3. Programmer dan tester keduanya saling bergantung satu sama lain.

\section{METODE PENELITIAN}

Untuk mendapatkan data dan informasi yang diperlukan dalam penulisan ini mengenai Sistem Informasi Pesawat Tanpa Awak (Drone) Berbasis Aplikasi Android, penulis menggunakan metode sebagai berikut :

\section{A. Observasi}

Dalam metode ini, penulis melakukan pengamatan dan interaksi langsung dengan orang-orang di sekitar pada saat menerbangkan drone. Sebagian besar dari pilot drone sudah mengetahui tentang regulasi menerbangkan drone, namun tetap saja mereka mencari cara untuk bisa menerbangkan drone-nya di daerah terlarang.

Pilot drone yang sudah mengetahui tentang regulasi penerbangan pun masih melanggar apalagi masyarakat yang baru mengenal drone mereka akan terbang sesuka hati tanpa tahu aturan yang berlaku.

\section{B. Studi Pustaka}

Penulis mengumpulkan data dengan cara membaca buku-buku di perpustakaan kampus Nusa Mandiri, internet, jurnal dan artikel-artikel yang ada kaitannya dengan judul penelitian sebagai refrensi data yang mendukung dalam pembuatan skripsi ini.

Untuk mengetahui mengenai peraturan atau hukum penggunaan drone di Indonesia, masyarakat mencari tahu melalui internet maupun buku. Dari ke-dua sumber itu munculah informasi-informasi seputar drone, namun tidak semua informasi ada di dalam satu situs atau buku. Masyarakat harus mencari pada situs atau buku lainnya untuk mendapatkan informasi yang dicari.

\section{Konsep Dasar Model Pengembangan Sistem}

Model Waterfall adalah model Software Development Life Cycle (SDLC) yang paling sederhana, model ini cocok untuk pengembangan perangkat lunak dengan spesifikasi yang tidak berubah-ubah[16].

Metode Waterfall memiliki tahapan-tahapan sebagai berikut[17] :

a. Requirements analysis and definition

Layanan sistem, kendala, dan tujuan ditetapkan oleh hasil konsultasi dengan pengguna yang kemudian didefinisikan secara rinci dan berfungsi sebagai spesifikasi sistem.

b. System and software design

Tahapan perancangan sistem mengalokasikan kebutuhan-kebutuhan sistem baik perangkat keras maupun perangkat lunak dengan membentuk arsitektur sistem secara keseluruhan. Perancangan perangkat lunak melibatkan identifikasi dan penggambaran abstraksi sistem dasar perangkat lunak dan hubungannya.

c. Implementation and unit testing

Pada tahap ini, perancangan perangkat lunak direalisasikan sebagai serangkaian program atau unit program. Pengujian melibatkan verifikasi bahwa setiap unit memenuhi spesifikasinya.

d. Integration and system testing

Unit-unit individu program atau program digabung dan diuji sebagai sebuah sistem lengkap untuk memastikan apakah sesuai dengan kebutuhan perangkat lunak atau tidak. Setelah pengujian, perangkat lunak dapat dikirimkan ke customer.

e. Operation and maintenance

Biasanya (walaupun tidak selalu), tahapan ini merupakan tahapan yang paling panjang. Sistem dipasang dan digunakan secara nyata. Maintenance melibatkan pembetulan kesalahan yang tidak ditemukan pada tahapan tahapan sebelumnya, meningkatkan implementasi dari

\section{JISICOM (Journal of Information System, Informatics and Computing)}

http://journal.stmikjayakarta.ac.id/index.php/jisicom Telp.+62-21-3905050, e-mail: jisicom@stmikjayakarta.ac.id, jisicom2017@gmail.com 


\section{Journal of Information System, Informatics and Computing}

unit sistem, dan meningkatkan layanan sistem sebagai kebutuhan baru.

Seperti itulah proses yang dilakukan oleh masyarakat untuk mendapatkan informasi mengenai drone, sangat menyita waktu tetapi apadaya cara tersebut harus tetap dilakukan jika ingin mengetahui mengenai informasi seputar drone.

C. Desain

1. Pemodelan UML

Gambar 2 adalah use case diagram dari aplikasi sisfo yang dibuat oleh penulis. Dalam use case diagram tersebut actor dalam hal ini sebagai pengguna, dapat memilih menu yang tersedia, seperti : Regulasi, Zona Merah, Jenis Drone, Tips, Tentang, dan Keluar.

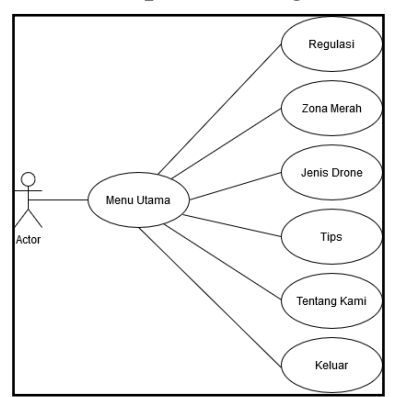

Gambar 1 Use Case Diagram

2. Activity Diagram

Activity Diagram merupakan gambaran alir dari aktivitas-aktivitas didalam sistem yang berjalan.

a. Activity Diagram Menu Regulasi

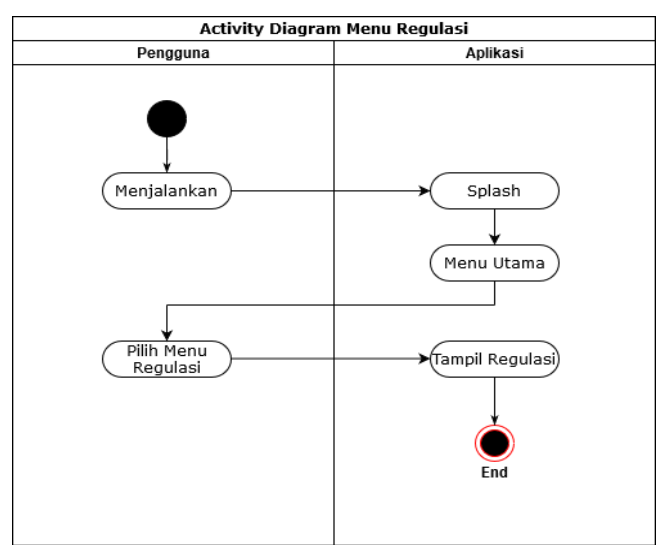

Gambar 2 Activity Diagram Menu Regulasi b. Activity Diagram Menu Zona Merah

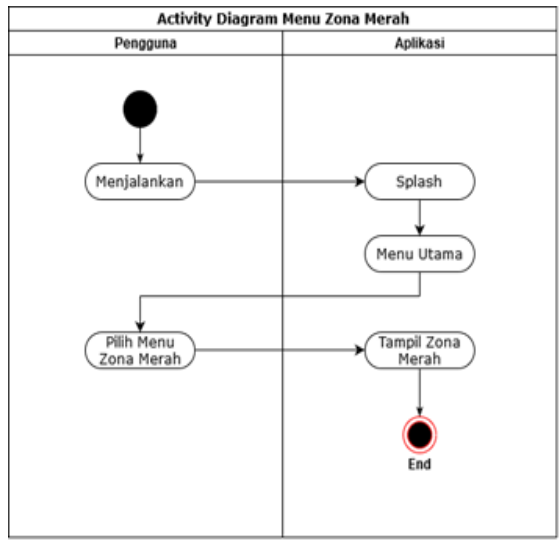

Gambar 3. Activity Diagram Menu Zona Merah

c. Activity Diagram Menu Jenis Drone

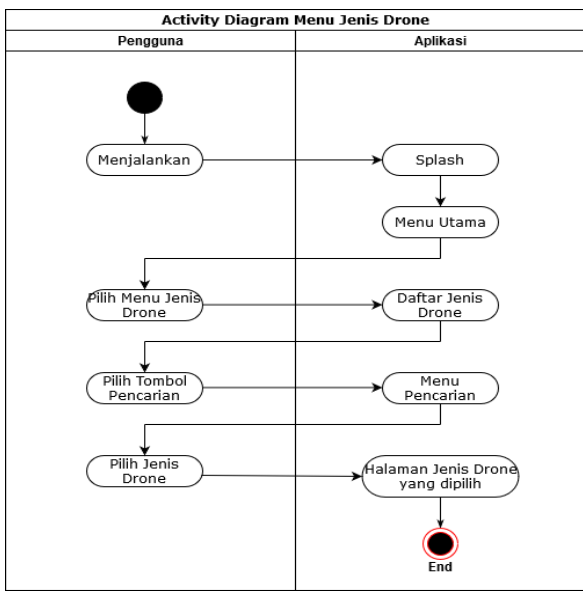

Gambar 4 Activity Diagram Menu Jenis Drone

3. Sequence Diagram

Sequence Diagram menggambarkan interaksi antar objek didalam dan di sekitar sistem yang berupa message yang digambarkan terhadap waktu.

JISICOM (Journal of Information System, Informatics and Computing)

http://journal.stmikjayakarta.ac.id/index.php/jisicom Telp.+62-21-3905050, e-mail: jisicom@stmikjayakarta.ac.id, jisicom2017@gmail.com 


\section{Journal of Information System, Informatics and Computing}

a) Sequence Diagram Menu Utama

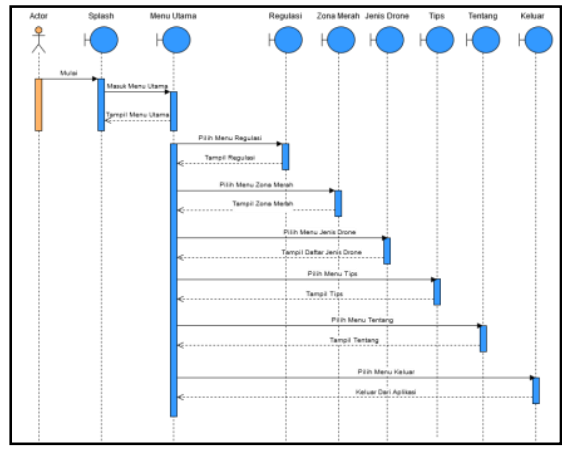

Gambar 4 Sequence Diagram Menu Utama

4. Deployment Diagram

Deployment diagram digunakan untuk menggambarkan, memvisualisasikan, menspesifikasikan serta mendokumentasikan suatu proses yang terjadi dalam sebuah sistem berbasis OOP (object orientied programming) yang akan dibangun[13].

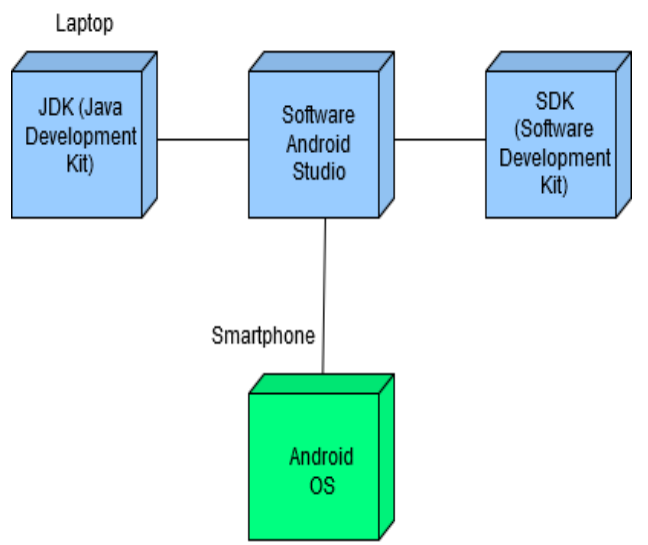

Gambar 5 Deployment Diagram

\section{HASIL DAN PEMBAHASAN}

1. nnterface

Gambar 6 merupakan interface/tampilan dari halaman utama aplikasi sistem informasi pesawat tanpa awak (drone) berbasis aplikasi android.

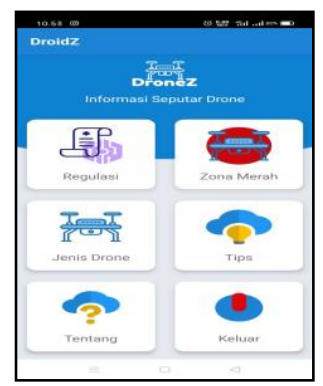

Gambar 6 Menu Utama

2. Tampilan Menu Regulasi

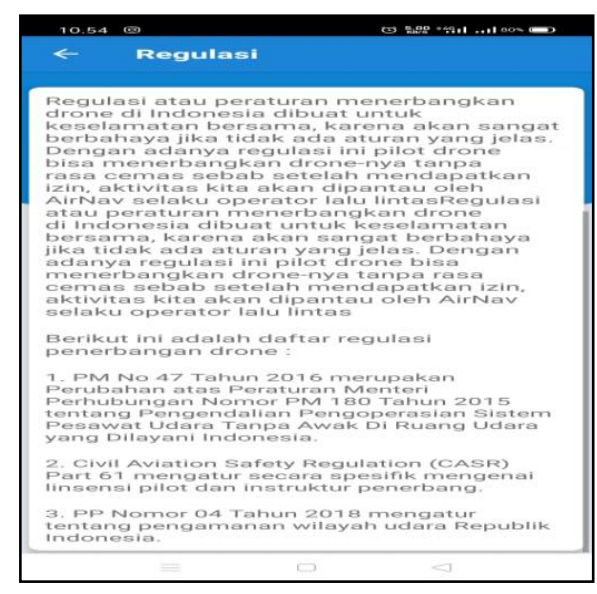

Gambar 7 Tampilan Menu Regulasi

\section{Tampilan Menu Zona Merah}

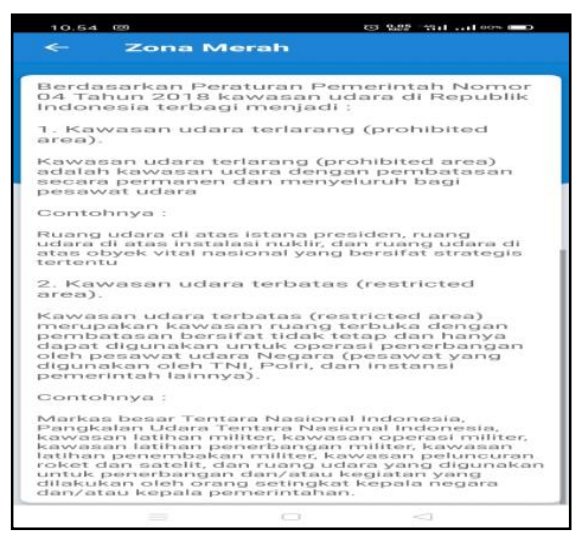

Gambar 8. Tampilan Menu Zona Merah

JISICOM (Journal of Information System, Informatics and Computing)

http://journal.stmikjayakarta.ac.id/index.php/jisicom Telp.+62-21-3905050, e-mail: jisicom@stmikjayakarta.ac.id, jisicom2017@gmail.com 


\section{Journal of Information System, Informatics and Computing}

\section{Tampilan Menu Jenis Drone}

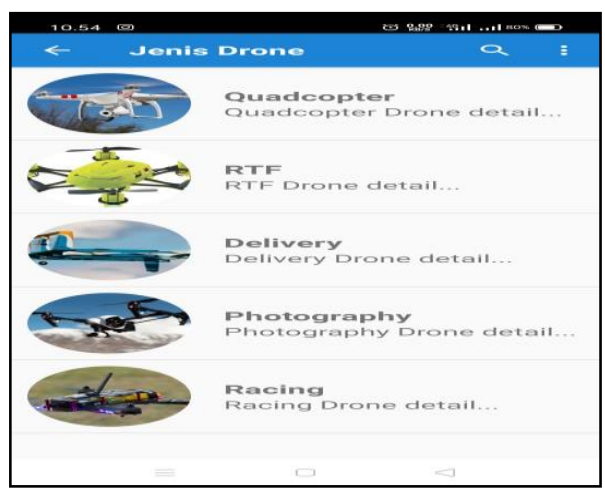

Gambar 9 Tampilan Menu Jenis Drone

5. Tampilan Fitur Search

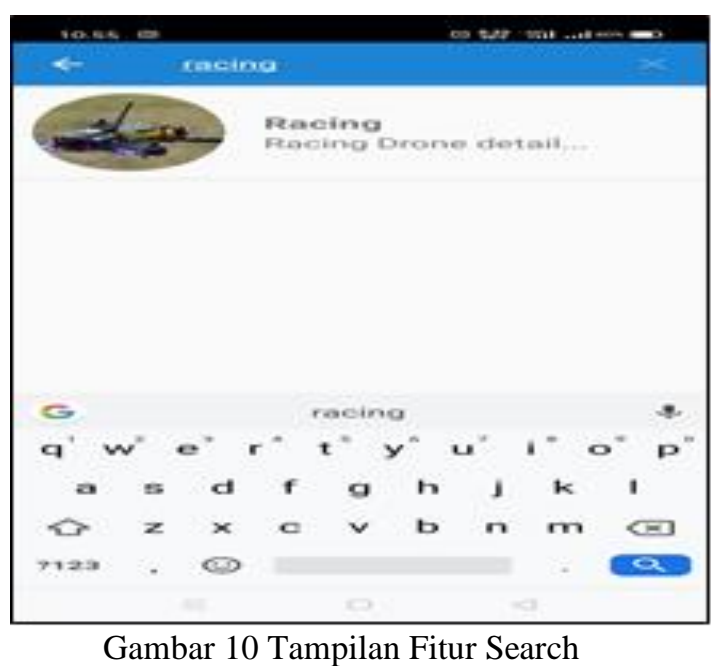

6. Pengujian

Pada tahapan ini penulis menggunakan metode black box testing.

\begin{tabular}{|c|c|c|c|c|}
\hline $\begin{array}{l}\mathbf{N} \\
\mathbf{0} \\
\cdot\end{array}$ & $\begin{array}{c}\text { Skena } \\
\text { rio }\end{array}$ & Test Case & $\begin{array}{c}\text { Hasil } \\
\text { yang } \\
\text { diharapk } \\
\text { an } \\
\end{array}$ & Ket. \\
\hline 1 & $\begin{array}{l}\text { Tampi } \\
1 \\
\text { Menu } \\
\text { Utama }\end{array}$ & $\begin{array}{l}\text { Menampilk } \\
\text { an } \\
\text { Halaman } \\
\text { Menu } \\
\text { Utama }\end{array}$ & $\begin{array}{l}\text { Tampil } \\
\text { Halaman } \\
\text { Menu } \\
\text { Utama }\end{array}$ & Berhasi \\
\hline 2 & $\begin{array}{l}\text { Memil } \\
\text { ih } \\
\text { Regul } \\
\text { asi }\end{array}$ & $\begin{array}{l}\text { Menampilk } \\
\text { an } \\
\text { Halaman } \\
\text { Regulasi }\end{array}$ & $\begin{array}{l}\text { Tampil } \\
\text { Halaman } \\
\text { Regulasi }\end{array}$ & Berhasi \\
\hline $\begin{array}{l}3 \\
.\end{array}$ & $\begin{array}{l}\text { Memil } \\
\text { ih } \\
\text { Zona } \\
\text { Merah }\end{array}$ & $\begin{array}{l}\text { Menampilk } \\
\text { an } \\
\text { Halaman } \\
\text { Zona } \\
\text { Merah }\end{array}$ & $\begin{array}{l}\text { Tampil } \\
\text { Halaman } \\
\text { Zona } \\
\text { Merah }\end{array}$ & Berhasi \\
\hline $\begin{array}{l}4 \\
.\end{array}$ & $\begin{array}{l}\text { Memil } \\
\text { ih } \\
\text { Jenis } \\
\text { Drone }\end{array}$ & $\begin{array}{l}\text { Menampilk } \\
\text { an Daftar } \\
\text { Jenis } \\
\text { Drone }\end{array}$ & $\begin{array}{l}\text { Tampil } \\
\text { Jenis- } \\
\text { Jenis } \\
\text { Drone } \\
\end{array}$ & Berhasi \\
\hline $\begin{array}{l}5 \\
.\end{array}$ & $\begin{array}{l}\text { Memil } \\
\text { ih } \\
\text { Daftar } \\
\text { Jenis } \\
\text { Drone }\end{array}$ & $\begin{array}{l}\text { Menampilk } \\
\text { an Jenis- } \\
\text { Jenis } \\
\text { Drone }\end{array}$ & $\begin{array}{l}\text { Tampil } \\
\text { Halaman } \\
\text { Jenis } \\
\text { Drone } \\
\text { yang } \\
\text { dipilih }\end{array}$ & Berhasi \\
\hline 6 & $\begin{array}{l}\text { Memil } \\
\text { ih } \\
\text { Tips }\end{array}$ & $\begin{array}{l}\text { Menampilk } \\
\text { an } \\
\text { Halaman } \\
\text { Tips }\end{array}$ & $\begin{array}{l}\text { Tampil } \\
\text { Halaman } \\
\text { Tips }\end{array}$ & Berhasi \\
\hline 7 & $\begin{array}{l}\text { Memil } \\
\text { ih } \\
\text { Tenta } \\
\text { ng }\end{array}$ & $\begin{array}{l}\text { Menampilk } \\
\text { an } \\
\text { Halaman } \\
\text { Tentang }\end{array}$ & $\begin{array}{l}\text { Tampil } \\
\text { Info } \\
\text { Tentang }\end{array}$ & Berhasi \\
\hline 8 & $\begin{array}{l}\text { Memil } \\
\text { ih } \\
\text { Kelua } \\
\mathrm{r}\end{array}$ & $\begin{array}{l}\text { Keluar dari } \\
\text { Menu } \\
\text { Utama }\end{array}$ & $\begin{array}{l}\text { Tampil } \\
\text { Halaman } \\
\text { Keluar }\end{array}$ & Berhasi \\
\hline
\end{tabular}

Table 1. Hasil Pengujian Black Box Testing 


\section{Journal of Information System, Informatics and Computing}

\section{KESIMPULAN}

Sesuai dengan uraian dan penjelasan pada $b a b-b a b$ sebelumnya dan dalam mengakhiri pembahasan "Sistem Informasi Pesawat Tanpa Awak (Drone) Berbasis Aplikasi Android" maka dapat diambil beberapa kesimpulan sebagai berikut:

1. Aplikasi ini menampilkan informasi seputar drone seperti : regulasi, zona merah, jenis-jenis drone, tips menerbangkan drone sesuai dengan aturan dan juga menampilkan informasi tentang penulis.

2. Aplikasi ini di lengkapi dengan fitur pencarian kata di menu jenis drone sehingga mempermudah pengguna dalam mencari jenis drone yang di inginkan.

3. Dengan adanya aplikasi ini membuat masyarakat mengetahui bahwa pesawat tanpa awak (drone) itu tidak bisa terbang disembarang tempat.

\section{REFERENASI}

[1] A. Suciani, "Pemanfaatan Drone DJI Phantom 4 Untuk Identifikasi Batas Administrasi Wilayah," J. Geogr., vol. 11, no. 2, pp. 218223, 2019.

[Accessed: 15-Apr-2020].

[2] M. G. Yoedtadi, "PENGGUNAAN DRONE PADA PELIPUTAN BERITA TELEVISI (Perspektif Wartawan Televisi Terhadap Etika Peliputan Menggunakan Drone)," J. Muara Ilmu Sos. Humaniora, dan Seni, vol. 3, no. 1, p. 54, 2019.

[Accessed: 25-Apr-2020].

[3] "DRONE REGULATION." [Online]. Available:

http://dephub.go.id/org/otbanwil2/post/read/reg ulasi-drone?language=id. [Accessed: 25-Apr2020].

[4] A. Gani and L. Marlinda, "Aplikasi Pembelajaran Trigonometri Berbasis Android Menggunakan Algoritma Fisher Yates Shuffle," J. Tek. Komput., vol. III, no. 2, pp. 114-119, 2017.

[Accessed: 01-Mei-2020].
[5] "Pengertian Program Secara Umum, Fungsi dan Jenis-Jenis Program." [Online]. Available: https://materibelajar.co.id/pengertian-program/. [Accessed: 01-May-2020].

[6] N. K. Ceryna Dewi, I. B. G. Anandita, K. J. Atmaja, and P. W. Aditama, "Rancang Bangun Aplikasi Mobile Siska Berbasis Android," SINTECH (Science Inf. Technol. J., vol. 1, no. 2, pp. 100-107, 2018.

[Accessed: 01-Mei-2020].

[7] S. Surahman and E. B. Setiawan, "Aplikasi Mobile Driver Online Berbasis Android Untuk Perusahaan Rental Kendaraan," J. Ultim. InfoSys, vol. 8, no. 1, pp. 35-42, 2017.

[Accessed: 01-Mei-2020].

[8] J. Andi, "Pembangunan Aplikasi Child Tracker Berbasis Assisted - Global Positioning System ( A-GPS ) Dengan Platform Android," J. Ilm. Komput. dan Inform., vol. 1, no. 1, pp. 1-8, 2015.

[Accessed: 01-Mei-2020].

[9] A. J. Maisyaroh, Astriana Mulyani, "Rancang Bangun Aplikasi Pembelajaran Tabel Periodik Unsur Kimia Berbasis Android," J. Momentum, vol. 17, no. 1, pp. 1-9, 2015.

[Accessed: 01-Mei-2020].

[11] R. Batopie, Kupas Tuntas Jendela Kerja Adobe Photoshop, vol. 53, no. 9. 2008.

[Accessed: 16-Mei-2020].

[12] M. T. Prihandoyo, "Unified Modeling Language (UML) Model Untuk Pengembangan Sistem Informasi Akademik Berbasis Web," J. Inform. J. Pengemb. IT, vol. 3, no. 1, pp. 126-129, 2018.

[Accessed: 16-Mei-2020].

[13] "Contoh Deployment Diagram (Dilengkapi Pengertian) - ngampus." [Online]. Available: https://ngampus.id/contoh-deploymentdiagram/. [Accessed: 14-Jul-2020].

[14] T. Hidayat and M. Muttaqin, "Pengujian Sistem Informasi Pendaftaran dan Pembayaran Wisuda Online menggunakan Black Box Testing dengan Metode Equivalence Partitioning dan Boundary Value Analysis," J. Tek. Inform. UNIS JUTIS, vol. 6, no. 1, pp. 2252-5351, 2018.

[Accessed: 16-Mei-2020].

[15] J. Dermawan, "Implementasi Model Waterfall Pada Pengembangan Berbasis Web Pada Sekolah Dasar Al-Azhar Syifa Budi Jatibening," Paradigma, vol. 19, no. 2, pp. 142-147, 2017.

[Accessed: 25-Apr-2020].

[16] G. W. Sasmito, "Penerapan Metode Waterfall

\section{JISICOM (Journal of Information System, Informatics and Computing)}

http://journal.stmikjayakarta.ac.id/index.php/jisicom Telp.+62-21-3905050, e-mail: jisicom@stmikjayakarta.ac.id, jisicom2017@gmail.com 
Pada Desain Sistem Informasi Geografis Industri Kabupaten Tegal," J. Inform. Pengemb. IT, vol. 2, no. 1, pp. 6-12, 2017.

[Accessed: 01-Mei-2020].

[17] T. S. Jaya, "Pengujian Aplikasi dengan Metode Blackbox Testing Boundary Value Analysis (Studi Kasus: Kantor Digital Politeknik Negeri Lampung)," J. Inform. Pengemb. IT, vol. 3, no.

2, pp. 45-46, 2018. [Accessed: 16-Mei-2020]. 